\title{
Self care practices of menstrual hygiene among adolescents school going girls in Amassoma Community, Bayelsa State
}

\author{
Adika, V. O. ${ }^{1 \star}$, Ayinde M. $0^{2}$ and Jack-Ide I. $0^{3}$ \\ ${ }^{1}$ Department of Medical Surgical Nursing, Faculty of Nursing, Niger Delta University, Wilberforce Island, \\ Bayelsa State, Nigeria. \\ ${ }^{2}$ Faculty of Nursing, College of Health Sciences, Niger Delta University, Wilberforce Island, Bayelsa State, Nigeria. \\ ${ }^{3}$ Department of Mental and Psychiatry Nursing, Faculty of Nursing, Niger Delta University, Wilberforce Island, \\ Bayelsa State, Nigeria.
}

Accepted 21 May, 2013

\begin{abstract}
Self care practices as well as menstrual hygiene are basic requirements for promoting a satisfied life and personal esteem in a woman. It is therefore necessary to investigate the self care practice of menstrual hygiene among female school going adolescents who have attained menarche in Amassoma community, Bayelsa State. A survey was designed with systematic sampling which involves selection of girls from government and private secondary schools. A total of two hundred and nine $(n=209)$ students participated in the study after the aim of the study was explained, and their consent obtained. A carefully constructed questionnaire was administered to the related classes. Results indicated that adolescent's girls have an average level of self care and menstrual hygiene, even though age and educational status did not significantly impact on the effect of self care practice and menstrual hygiene. This therefore calls for more education about this special aspect of these adolescent school girls' life and reproductive life.
\end{abstract}

Key words: Menstrual hygiene, self care practice, adolescent girls, Bayelsa.

\section{INTRODUCTION}

Adolescent has been defined by the World Health Organization (WHO) as the period between 10 to 19 years of age, in their second decade of life (WHO, 2007). Adolescent girlhood is a critical time of identity formation and a period of transition from childhood to womanhood (Kirk and Sommer, 2005) and of great challenge to the parents, as well as the child and those concerned for the upbringing of the adolescent. It is characterized by physical, psychological, mental and social changes that are critical to wellbeing (Szilagyi, 2003).

Adolescent menstrual hygiene and self care is a critical issue that determines the health status of the adolescent and the eventual practices that are inculcated into adult life (Uzochukwu et al., 2009). Poor hygiene and inadequate self-care practices are major determinants of morbidity and other complications among this age group (McCaleb and Cull, 2000). However, some girls have developed their own strategy to cope. Globally, different forms of beliefs and perception of menstruation have been found which either negates or promotes the adolescent females health. Studies have shown that superstitions, illogical beliefs and misinterpretation are more common than accurate understanding of the process of menstruation, menstrual hygiene and self care practices (Uzochukwu et al., 2009).

In view of this, it becomes important for parents, teachers and health care practitioners especially nurses to be adequately involved in the promotion of adolescent 
menstrual hygiene and self care practices to reduce disease burden and poor health outcome associated with poor menstrual hygiene and self care among these group.

Among the ljaw people of south-south Nigeria, Bayelsa state data on adolescent menstrual hygiene and care practices are scarce, except the work of Adika et al. (2011) on use of sanitary pads among adolescent girls. In other to curtail diseases such as vaginal infections that may result to pelvic inflammatory diseases with dare consequences, it becomes eminent to investigate adolescents' menstrual hygiene and self care practices in Amassoma community of Bayelsa.

Menstruation and menstrual hygiene are still clouded by taboos and socio-cultural restrictions resulting in adolescent girls remaining ignorant of the scientific facts and hygienic practices which sometimes results into adverse health outcomes (Dasgupta and Sarkar, 2008; ElGilany and Nadawi, 2005; Poureslami and Osateashtiani, 2002). Poor menstrual hygiene and self care practices are synonymous to poor health outcome and health status of the adolescent female (Uzochukwu et al., 2009). Unlike in previous generations where adolescent is seen as a period of cleanliness and spotlessness, this observation rarely applies to adolescents of these days. The increasing rise in female genital tract infections among women in recent times really speaks of poor hygiene and self care practices. This trends and observations may be similar to what is obtainable in Amassoma, Bayelsa state. Therefore, there is the need to investigate adolescent menstrual hygiene and self care practices among this group. The main objectives for this study are:

1. To determine the self care practices associated with menstrual hygiene among adolescents in Amassoma community.

2. To determine their perception of menstruation.

To determine what factors influence their self care practice of menstrual hygiene. The formulated hypothesis to be investigated in this study is;

$\mathbf{H}_{0}$ : There is no statistical significant relationship between age and effect of menstruation on self care

\section{MATERIALS AND METHODS}

Amassoma community is where the Niger Delta University is located, in the south-south geo-political zone, Nigeria. There are different cadres of workers and their families living in the community, from native fisher men and business men, to other government workers. There are bustling activities because of the site of the university, primary schools and secondary schools in this area. In this descriptive survey study, 209 adolescent girls were purposefully selected at random from two schools, from a list of schools in Amassoma community. The inclusion criteria were that they have attained menarche and are taking care of themselves during menses. The classes of Junior Secondary School (1 to 3) and Senior Secondary School (1 to 3) were targeted, and students were then informed about the aim of the study. The study tool was a carefully designed, tested, self-structured questionnaire developed and written in English language by the researchers to elicit information aimed at meeting the criteria of the purpose for the study. It is made up of three (3) sections: A, B and C.

Section A obtains information on socio-demographic variable of respondents while section $B$ on menstrual hygiene and section $C$ obtains information related to self care practices. The validity of the instrument was ascertained from the information gathered from the literatures that met the study criteria, and also involving an expert in research for the questionnaire suitability and its applicability for the study gave credibility of the instrument. The reliability of instrument was determined through a test-retest method involving carrying out a pilot study using 20 questionnaires in a nearby community (Ogobiri) under the same local government as Amassoma and including newly observed facts while discarding ambiguous items of the initially constructed questionnaire. Then, 120 questions were administered face to face to all respondents and were retrieved immediately by the investigators. This lasted for 1 month from June to July, 2012. Data obtained from the field work were analyzed by means of the statistical package for social sciences (SPSS) version 17 Chicago IL. Descriptive and inferential statistics were calculated for socio-demographics, respondents' level of menstrual hygiene and self care practices while chi-square was used for inferential statistics of studied parameters. A letter of authority seeking permission to undertake the study was issued to the schools and chief of the community, respectively, who gave the researchers a verbal consent to conduct the study and explained also to the adolescent school girls to comply. The purpose of the study was explained to the participants and confidentiality was assured.

\section{RESULT AND DATA PRESENTATION}

\section{Socio-demographic data}

Table 1 shows the socio-demographic data of respondents. A total of two hundred and nine $(n=209)$ adolescents were involved in the study whose age range was 10 to 19 years, and a mean age of 13.7 years. 190 $(90.9 \%)$ of the adolescents were Christians, 14 (6.7\%) were Muslims, $3(1.4 \%)$ belong to African traditional religion while, $2(1.0 \%)$ belonged to other religion; 100 $(47.8 \%)$ are in senior secondary school while 109 $(52.2 \%)$ are in junior secondary school; age of menarche are $77(36.8 \%)$ at 9 to 12 years, $115(55.0 \%)$ at 13 to 15 , $16(7.7 \%)$ at 16 to 17 and $1(0.5 \%)$ attained menarche at the age of 18 to 19 years.

\section{Perception of menstruation}

Table 2 shows respondents knowledge on the meaning of menstruation: $114(54.5 \%)$ perceived that menstruation is regular monthly flow of blood from the female genital tract while the remaining (45.5\%) did not know this, 123 $(58.9 \%)$ thought menstruation means bleeding from the vagina while the remaining $86(41.1 \%)$ did not know this. Also, $101(48.3 \%)$ knew that menstruation is also referred to as "the period" while the remaining $108(51.7 \%)$ did not know this among the adolescent female respondents. 
Table 1. Socio-demographic data of respondents $(n=209)$.

\begin{tabular}{lcc}
\hline Variable & Frequency & Percentage \\
\hline Age & & \\
$10-11$ & 11 & 5.2 \\
$12-13$ & 89 & 42.6 \\
$14-15$ & 70 & 33.4 \\
$16-17$ & 36 & 17.2 \\
$18-19$ & 2 & 1.4 \\
& & \\
Religion & & \\
Christian & 190 & 90.9 \\
Muslim & 14 & 6.7 \\
African tradition & 3 & 1.4 \\
Others & 2 & 1.0 \\
& & \\
Education & & \\
Junior Secondary School & 109 & 52.2 \\
Senior Secondary School & 100 & 47.8 \\
& & \\
Menarche age & & \\
$9-12$ & 77 & 36.8 \\
13-15 & 115 & 55.0 \\
$16-17$ & 16 & 7.7 \\
$18-19$ & 1 & 0.5 \\
\hline
\end{tabular}

\section{Self care practice during menstruation}

Table 3 shows the self care practice during menstruation: $63(30.1 \%)$ stay at home during menstruation while 146 $(69.9 \%)$ do not stay at home during menstruation. 112 $(53.6 \%)$ use sanitary pads during menstruation whereas $97(46.4 \%)$ do not use sanitary pads, 96 (45.9\%) uses deodorant while $113(54.1 \%)$ do not use deodorants, 185 $(88.5 \%)$ wash their underwear while $73(34.9 \%)$ do not wash their under wears, $161(77.0 \%)$ change their under wears while $48(23.0 \%)$ do not change their under wears during menstruation.139 $(77.0 \%)$ said yes they shave their genital area during menstruation, while73 (34.9\%) do not shave their genital areas. However, 127 (60.8\%) engage in regular bathing to preserve their genital hygiene while $31(14.8 \%)$ used regular bathing during menstruation to preserve their hygiene while the remaining $51(24.4 \%)$ engage both in frequent bath and regular change of sanitary pads to preserve their menstrual hygiene.

\section{Reasons for self care practice}

Table 4 shows reasons for self care practices: 142 $(67.9 \%)$ of the adolescent girls reported yes to prevent infections as reason for their self care practice while 67 (32.1\%) say no to prevent infection, as not a reason for self care practice. $129(61.7 \%)$ reported yes to promote health as reason for self care practice while $80(38.3 \%)$ said no to promote health, as not a reason for self care practice, $181(86.6 \%)$ said yes to avoid body odour as a reason for self care while $28(13.4 \%)$ said no to avoid odour as a reason for self care practice.

\section{Factors that influences self care practices}

Table 5 shows the various factors that influence adolescent self care practice; $144(68.9 \%)$ of the adolescent girls said yes to be influenced by underage while the remaining $65(31.1 \%)$ said no to be influenced by underage, $131(62.7 \%)$ stated yes to be influenced by ill health of the adolescent girls while the remaining 78 $(37.3 \%)$ said no to be influenced by ill health or illness, 91 $(43.5 \%)$ of the adolescent girls reported busy schedule to influence self care practice while the remaining 118 $(56.5 \%)$ said no to be influenced by busy schedules, 89 $(42.6 \%)$ stated yes to be influenced by financial constrains while 120 (57.4\%) said no be influenced by financial constrains, and 96 (45.9\%) said yes menstrual cycle influence self care practices whereas the other 113 $(54.1 \%)$ said no to the influence of menstrual cycle.

\section{Relationship between age and effect of menstruation self care}

Table 6 shows the relationship between age and effect of menstruation on self care. There was no statistical significant relationship between adolescent age and the impact of menstruation on self care practices as $p$-value $=0.65$.

\section{DISCUSSION}

Optimal care of menstrual hygiene are synonymous to good hygiene practices and inevitably to a healthy living in an adolescent girl's life (Adika et al., 2011). The result from this study was drawn from adolescent females resident in Amassoma, Bayelsa state, Nigeria. The discussions of findings are:

\section{Social demography}

A total of two hundred and nine $(n=209)$ adolescent females who have attained menarche were included in the study, 109 were in Junior secondary school and 100 in Senior secondary school, whose age range was from 10 to 19 years and were mostly of 12 to 13 years old, and were Christians by religion, resident in Amassoma community (Table 1). 
Table 2. Perception of menstruation among female adolescents $(n=209)$.

\begin{tabular}{lcc}
\hline Variable & Frequency & Percentage \\
\hline Menstruation is regular monthly flow of blood & & \\
Yes & 114 & 54.5 \\
No & 95 & 45.5 \\
Menstruation is bleeding from vagina & & \\
Yes & 123 & 58.9 \\
No & 86 & 41.1 \\
Menstruation is the period & & \\
Yes & 101 & 48.3 \\
No & 106 & 51.7 \\
\hline
\end{tabular}

Table 3. Self care practice during menstruation among adolescent $(n=209)$.

\begin{tabular}{lcc}
\hline Variable & Frequency & Percentage \\
\hline How do you preserve your hygiene during menstruation & & \\
Regular bathing & 127 & 60.8 \\
Frequent pad/toilet & 31 & 14.8 \\
Both & 51 & 24.4 \\
Stay indoors at home & & \\
Yes & 64 & 30.6 \\
No & 145 & 69.4 \\
Use of sanitary pads & & \\
Yes & 112 & 53.6 \\
No & 97 & 46.4 \\
Use of deodorant & & \\
Yes & 96 & 45.9 \\
No & 113 & 54.1 \\
Washing under wears & & \\
Yes & 185 & 88.5 \\
No & 24 & 11.5 \\
Shaving the genital area & & \\
Yes & 139 & 65.1 \\
No & 73 & 34.9 \\
Changing under wear & & \\
Yes & 161 & 77.0 \\
No & 48 & 23.0 \\
\hline
\end{tabular}

\section{Self care practice of menstrual hygiene}

The practice of healthier behavior like menstrual hygiene and self care practices during normal menstruation, menorrhea (heavy bleeding) and dysmenorrheal (painful bleeding) are important indicators of health and determinant of health especially during the reproductive age of a woman (Singh et al., 2011), as adoption of high quality menstrual hygiene will play an important role in prevention of reproductive tract infections (RTI) and cancer of cervix among the women population. Therefore, promoting positive attitudes towards management of menstruation and related problems among the adolescent girls is the need of the hour (Ray and Dasgupta, 
Table 4. Reasons for self practice $(n=209)$.

\begin{tabular}{lcc}
\hline Variable & Frequency & Percentage \\
\hline Prevent infection & & \\
Yes & 142 & 67.9 \\
No & 67 & 32.1 \\
Promote health & & \\
Yes & 129 & 61.7 \\
No & 80 & 38.3 \\
Avoid body odour & & \\
Yes & 181 & 86.6 \\
No & 28 & 13.4 \\
\hline
\end{tabular}

Table 5. Factors that Influence self care practices.

\begin{tabular}{lcc}
\hline Variable & Frequency & Percentage \\
\hline Under age & & \\
Yes & 144 & 68.9 \\
No & 65 & 31.1 \\
III health & & \\
Yes & 131 & 62.7 \\
No & 78 & 37.3 \\
Busy schedule & & \\
Yes & 89 & 43.5 \\
No & 120 & 56.5 \\
Financial constrains & & \\
Yes & 89 & 42.6 \\
No & 120 & 57.4 \\
Menstrual cycle & & \\
Yes & & \\
No & 93 & 45.9 \\
\hline
\end{tabular}

Table 6. Relationship between age and effect of menstruation on self care.

\begin{tabular}{|c|c|c|c|c|c|}
\hline \multirow{2}{*}{ Age distribution } & \multicolumn{2}{|c|}{ Do menstruation affect self care practice } & \multirow{2}{*}{$\mathrm{X}^{2-}$ Value } & \multirow{2}{*}{ Df } & \multirow{2}{*}{ P-Value } \\
\hline & Yes & No & & & \\
\hline 10 & 1 & 2 & \multirow{11}{*}{17.471} & \multirow{11}{*}{10} & \multirow{11}{*}{0.65} \\
\hline 11 & 8 & 2 & & & \\
\hline 12 & 18 & 19 & & & \\
\hline 13 & 23 & 29 & & & \\
\hline 14 & 17 & 35 & & & \\
\hline 15 & 11 & 7 & & & \\
\hline 16 & 13 & 9 & & & \\
\hline 17 & 4 & 10 & & & \\
\hline 18 & 0 & 1 & & & \\
\hline 19 & 0 & 1 & & & \\
\hline 20 & 1 & 0 & & & \\
\hline
\end{tabular}


2012), which concurs with the results of this study. Table 3 reveals that self care practice during menstruation includes: regular washing of under wears $(88.5 \%)$, regular changing of under wear $(77.0 \%)$, shaving the genital area $(65.1 \%)$, regular bath $(60.8 \%)$, use of sanitary pads $(53.6 \%)$, use of deodorant $(45.9 \%)$ and relaxation at home $(30.1 \%)$ but however, this indicate a sub-optimal level of care during menstruation.

A similar finding was observed by Singh and Maya (2006) in their study on knowledge assessment regarding puberty and menstruation among adolescent school girls in Varanasi district, India. Again, Adika et al. (2011) observed a poor perception and behavior towards the use of sanitary pads during menstruation among adolescent school going girls which is similar to the result of this study, as they noted that lack of finance was responsible for non-usage of sanitary pads and hence the use of ether absorbent such as clothes. Regardless of this findings, many of the studied females did not have appropriate knowledge about the menstrual period hygiene, and did not practice health-oriented behavior in this regard (Ray and Dasgupta, 2012). This also supports our study finding.

\section{The perception of menstrual hygiene}

Table 2 showed perception of menstruation among female adolescents. The results indicated that $54.5 \%$ of respondents perceive menstruation to mean regular monthly flow of blood from the female genital tract. Furthermore, (48.3\%) of the respondents perceive menstruation to mean what is called period while another group of respondents (58.9\%) perceived menstruation to mean the same thing as bleeding from the vagina. This implies that some adolescent girls in Amassoma community have poor perception of the meaning of menstruation, as almost $(45.5 \%)$ of them do not know that menstruation is the physiological menstrual flow of blood, and over half $(58.9 \%)$ of them thought menstruation is bleeding from vagina, and less than half $(48.3 \%)$ knew menstruation to be synonymous with the period. This finding is in concordance with a study conducted by Ali et al. (2010) in Pakistan that reported a 50\% level of knowledge on menstruation among adolescent girls. Similarly, Uzochukwu et al. (2009) found similar poor knowledge among adolescents and the need to provide premenarcheal training on menstrual practices and hygiene for Nigerian school girls.

\section{Factors influencing care practice of menstrual hygiene}

Factors such as under age (68.9\%), ill health $(62.7 \%)$, busy schedule $(43.5 \%)$, financial constrains $(42.6 \%)$ and menstrual cycle $(45.9 \%)$ were stated to influence menstrual hygiene habits and practices. No statistical significant relationship was observed between age, educational status and adolescent menstrual hygiene and self care practice. These findings are in concordance with the study by Adika et al. (2011) in their study on use of sanitary pad among adolescent girls in Amassoma community, Bayelsa state, Nigeria. The findings are also supported by the study of McCaleb and Cull (2000) on socio-cultural influence and self care practices of middle aged adolescents. However, Ravindran (2008) found that there was a significant association between menstrual hygiene maintenance and education, socioeconomic status, knowledge prior to menarche, type of protection, accessibility to water, bathroom facilities and menstrual disorders. These findings shows the essence of proper premenacheal training in schools to ensure acceptable levels of menstrual hygiene among adolescent school going girls to enable them obtain optimal self care practice and also for reforms and maintenance of good health and development.

\section{Nursing implication}

Nurses play a key role central to public education on health hygiene and personal development, including the maintenance of optimal menstrual hygiene and self care practices among female adolescents. They always come in contact with this vulnerable group and therefore it is necessary for them to have adequate knowledge as well as becoming role models to this deliquescent group of the society. It thus becomes as a role to ensure proper education and encouragement of personal hygiene and optimal self care practices among female adolescents in our society.

In summary, our results suggest that despite, the majority use of sanitary pads, there are no adequate self care practices and menstrual hygiene among the adolescent girls. Factors such as their financial status, ill health conditions and busy schedules were indicated to influence self care practice and menstrual hygiene. Our results further suggest that to promote health, avoid infections and prevent odors were reasons for self care practice and menstrual hygiene. Self care habits and practices have the potential to hamper the adolescent girls' reproductive development, thus highly important for their reproductive health and wellbeing. Self care practices in menstrual hygiene may help us not only to better understand self care practices, but to also find the most effective intervention among these vulnerable groups of adolescent girls and reduce their burden on menstrual hygiene.

\section{Conclusion}

Menstrual hygiene and self care practices have been investigated among adolescent school going girls in Amassomacommunity, BayelsaState. The findings indicate 
an average level of practice of self care among adolescent during menstruation. Factors such as age, religion and educational status were known to have no effect among respondents of this study. Improved level of menstrual hygiene and practice is encouraged among the study group.

\section{RECOMMENDATION}

The findings from this study made the researchers to make the following recommendation.

1. Menstrual hygiene and self care practice guide should be taught by teachers and easily practicable at home by their parents (mothers), sisters and experienced neighbors with a provision of listenable ears to the adolescents girls needs to avoid poor health outcome due to poor self care practices.

2. Menstrual hygiene and self care practices should be included in the curriculum of secondary school training.

3. Campaigns and seminars to improve adolescent menstrual hygiene and self care should be organized by teachers and parents association, as well as health care organization.

4. Sanitary pads should be made available by the government, the office of women affairs and gender matters to all adolescent females, and the need for regular bathing and change of pads should be emphasized by their teachers and school health visitors.

\section{REFERENCES}

Adika VO, Yagba J, Apiyanteide AF, Ologidi PW, Ekpo KE (2011). Perception and behavior on use of sanitary pads during menstruation among adolescent school girls in Bayelsa State, Nigeria. Adv. Appl. Sci. Res. 2(6):9-15

Ali TS, Rizvi NS (2010). Menstrual knowledge and practices of female adolescents in urban Karachi, Pakistan. J. Adolesc. 33(4):531-541.

Ravindran S (2008). Menstrual hygiene practices and Reproductive morbidity-A Community Based Survey in Rural Thiruvananthapuram, Kerala. Sree Chitra Tirunal $p 12$.

Dasgupta A, Sarkar M (2008). Menstrual hygiene: How hygienic is the adolescent girls? Indian J. Community Med. 33(2):77-80.

Ei-Gilanya A, Badawi K, El- Fedawy S (2005). Menstrual hygiene among adolescent school girls in Mansoura, Egypt. Reprod. Health Matters 13(26):147-152.

Kirk J, Sommer M (2005). Menstruation and body awareness: critical issues for girls' education. EQUALS 15:4-5.

McCaleb A, Cull VV (2000). Socio-cultural influences and self care practices of middle adolescents. J. Pediatr. Nurs. 15(1):30-35.

Poureslami M, Osati AF (2002). Attitude of female adolescents' dysmenorrhoea and menstrual hygiene in Tehran suburbs. Arch. Iranian Med. 5:377-396.
Ray S, Dasgupta A (2012). Determinants of Menstrual Hygiene among Adolescent Girls: A multivariate analysis. Natl. J. Commun. Med. 3(2):294-301.

Singh SP, Singh M, Arora M, Sen P (2006). Knowledge Assessment regarding Puberty and Menstruation among School Adolescent Girls of District Varanasi, (U.P.). Indian J. Prev. Soc. Med. 37(1,2): 9-1.

Singh S, Kandpal SD, Roy D (2011). Menstrual Hygiene Practices and RTI among ever-married women in rural slum. Indian J. Commun. Health 22:2, 23:1

Szilagyi PG (2003). Care of Children with special health care needs. Future Child 13(1):137-151.

Uzochukwu UA, Patricia NA, Theophilus ON (2009). The impact of premenarcheal training on menstrual practices and hygiene of Nigerian school girls. Pan Afr. Med. J. 22:9.

World Health Organization (WHO) (2007). Adolescent pregnancy Unmet needs and undone deeds. A review of the literature and programmes. Issues in Adolescent Health and Development, WHO, Geneva. 